\title{
Noncatalytic Direct Liquefaction of Biorefinery Lignin by Ethanol
}

Nielsen, Joachim Bachmann; Jensen, Anders; Madsen, Line Riis; Larsen, Flemming H.; Felby, Claus; Jensen, Anker Degn

Published in:

Energy and Fuels

Link to article, DOI:

10.1021/acs.energyfuels.7b00968

Publication date:

2017

Document Version

Peer reviewed version

Link back to DTU Orbit

Citation (APA):

Nielsen, J. B., Jensen, A., Madsen, L. R., Larsen, F. H., Felby, C., \& Jensen, A. D. (2017). Noncatalytic Direct Liquefaction of Biorefinery Lignin by Ethanol. Energy and Fuels, 31(7), 7223-7233.

https://doi.org/10.1021/acs.energyfuels.7b00968

\section{General rights}

Copyright and moral rights for the publications made accessible in the public portal are retained by the authors and/or other copyright owners and it is a condition of accessing publications that users recognise and abide by the legal requirements associated with these rights.

- Users may download and print one copy of any publication from the public portal for the purpose of private study or research.

- You may not further distribute the material or use it for any profit-making activity or commercial gain

- You may freely distribute the URL identifying the publication in the public portal

If you believe that this document breaches copyright please contact us providing details, and we will remove access to the work immediately and investigate your claim 


\section{Non-Catalytic Direct Liquefaction of Biorefinery}

\section{Lignin by Ethanol}

Joachim B. Nielsen, ${ }^{a}$ Anders Jensen, ${ }^{b}$ Line R. Madsen, ${ }^{a}$ Flemming H. Larsen, ${ }^{c}$ Claus Felby ${ }^{* b}$ and Anker D. Jensen ${ }^{* a}$

a Department of Chemical and Biochemical Engineering, Technical University of Denmark, Søltofts Plads 229, 2800 Kgs. Lyngby, Denmark. E-mail: aj@kt.dtu.dk

b Department of Geosciences and Natural Resource Management, University of Copenhagen, Rolighedsvej 23, 1958 Frederiksberg C, Denmark. E-mail: cf@ign.ku.dk

c Department of Food Science, University of Copenhagen, Rolighedsvej 30, 1958 Frederiksberg C, Denmark.

KEYWORDS

Lignin, direct liquefaction, solvolysis, bio-oil, diesel, ethanol, biorefinery

\section{ABSTRACT}

There is a growing interest in lignin valorization to biofuels and chemicals. Here we propose a novel and simple non-catalytic process to directly liquefy lignin rich solid residual from $2^{\text {nd }}$ Generation bio-ethanol production by solvolysis with ethanol. Through an extensive parameter study in batch autoclaves assessing the effects of varying reaction temperature, reaction time and 
solvent:lignin ratio, it is shown that hydrothermally pretreated enzymatic hydrolysis lignin solvolysis in supercritical ethanol can produce a heptane soluble bio-oil without the need for exhaustive deoxygenation. The process does not require addition of catalyst or a reducing agent such as hydrogen. The process is advantageously carried out with a low reaction period ( $<1$ hour) and with a reduced amount of solvent to lignin feedstock (ethanol:lignin (w/w) ratio of 2:1) which is a previously unexplored domain for lignin solvolysis. The resulting bio-oil product is mainly a mixture of di- and monomeric lignin species where the original lignin unit linkages have been broken. The oxygen content is lowered to $<10 \mathrm{wt} \%$ (corresponding to a HHV of 36 $\mathrm{MJ} / \mathrm{kg}$ ) and the bio-oil is stable and acid free (verified by NMR) and due to the use of sulfur free lignin rich residual as feedstock the resulting oil product is equally sulfur free. The residual solid product (char) has a reduced oxygen content relative to the lignin feed and equally increased higher heating value making it a candidate for use as a biochar.

TEXT

\section{Introduction}

The mitigation of fossil fuel induced climate change is the major technological and societal challenge of the $21^{\text {st }}$ century. Biofuels are part of the solution to reduce $\mathrm{CO}_{2}$ emissions from trucks, shipping and aviation, as there are no other realistic alternative fuel technologies. The production of $2^{\text {nd }}$ generation bio-ethanol converts non-edible plant biomass to a sustainable liquid fuel. The lignin, comprising up to $30 \%$ of the plant biomass, is the biggest by-product from this process. Currently lignin is simply burned as a low value solid fuel substituting coal. ${ }^{1}$ 
Research into lignin valorization often targets fine chemical production ${ }^{2,3}$; however, such processes often have low yields of specific compounds and require difficult and expensive separation. A different approach may be to utilize the heterogeneous nature of the lignin polymer in a reductive depolymerization as a path towards fuel products. This often involves catalysts and hydrogen for exhaustive deoxygenation adding to the cost and process complexity. ${ }^{4}$ Therefore a simple non-catalytic process for lignin liquefaction that yields a bio-crude that directly blends with fossil fuels, is needed. This is particularly relevant for combustion in large two-stroke engines, such as those found aboard large ships, as these are adapted to crude fuels. In this context, it is highly relevant that biorefinery lignin in particular provides a substrate for production of sulfur-free biofuels, as environmental demands for low sulfur emissions from ships in coastal areas are increasing. Kraft lignin is the most abundant lignin produced worldwide; ${ }^{5}$ however, the sulfur content means that catalytic processing is likely required for Kraft lignin-based fuel production.

Use of lignin rich feedstocks instead of whole biomass is a challenge in pyrolysis technologies, as it typically results in lower oil yields and increased charring. ${ }^{6}$ Solvolysis of lignin by alcohols is an alternative to pyrolysis. In particular lignin solvolysis by ethanol would allow for integration into existing biorefineries, as both lignin and ethanol are product streams (see Figure 1).

Lignin solvolysis by alcohols is not fully understood. However, several studies have highlighted the reductive depolymerization of lignin due to the alcohol facilitating direct cleavage of ether linkages ${ }^{7,8}$ and hydrogen donating effects. ${ }^{8-10}$ It is also widely established that alcohols inhibit repolymerization reactions. ${ }^{9,}{ }^{11-14}$ It is often reported in literature ${ }^{4,15}$, 
that the alcohol solvent should be supercritical to ensure the highest liquefaction yield. Also an increase in reaction temperature results in increased liquid yield,7, 16, 17, and when the reaction severity is increased, a shorter reaction time is required.7, 18 Increased lignin:solvent ratio typically results in a decreased oil yield and no beneficial effects have been reported. The maximum reported lignin:solvent ratios include 2 - $15 \mathrm{~g}$ lignin per 100 ml primary alcohol solvent.14, 18-23 The solvent loss in lignin solvolysis is often not reported, even though low solvent consumption and high lignin loading are needed for a commercially viable process.

In this work, a residual lignin from a commercial biorefinery process was partly converted into a diesel-like fuel by subjecting it to solvolysis in supercritical ethanol using a batch autoclave at different reaction temperatures, reaction times and degrees of lignin loading. All of the reaction products were quantified and analyzed to reveal the effects of different processing parameters and provide information on mechanistic aspects of the reaction. Some of the experimental results have also been communicated in a patent application. $^{24}$

\section{Methods}

\section{Lignin Feedstock}

The biomass feedstock used for the solvolysis experiments was a lignin rich solid residual obtained from enzymatically hydrolyzed, hydrothermally pretreated wheat straw. A detailed compositional analysis is shown in Supporting Information. The biomass feedstock is denoted lignin in this study as it is comprised mainly of acid insoluble lignin (65 wt\%). The lignin is a fine dry powder with an ash content of $13-15 \mathrm{wt} \%$ and a moisture content 
of $2 \mathrm{wt} \%$. The lignin is considered "sulfur free" as no sulfur was detected by elemental analysis.

\section{Experimental Procedure}

A $500 \mathrm{ml}$ stirred HT 4575 Parr batch autoclave was used for all of the solvolysis experiments. A series of experiments were conducted at $250-450{ }^{\circ} \mathrm{C}$ reaction temperature, 0 - $8 \mathrm{~h}$ reaction time and $0-40 \mathrm{~g}$ lignin rich solid residual in $100 \mathrm{ml}$ ethanol solvent. A stainless steel liner was fitted inside the vessel for easier product removal after reaction. A pre-weighed amount of lignin $(0-40 \mathrm{~g})$ and $100 \mathrm{ml}$ of ethanol solvent $(99.9 \%$, Sigma-Aldrich) were added to the vessel prior to sealing. The atmosphere inside the vessel was flushed three times with nitrogen to create a non-pressurized inert atmosphere prior to heating. Heating was applied through an electric heating jacket with a rate of $5-10$ ${ }^{\circ} \mathrm{C} / \mathrm{min}$. Constant stirring was applied during heat-up and maintained throughout the experiment. When the desired set point for the internal temperature of the vessel was reached the reaction period was defined to begin. At supercritical solvent conditions $\left(T_{c}\right.$ $=241^{\circ} \mathrm{C}$ ) there is no distinct vapor and liquid phase, why the solvent occupies the entire internal volume of the reaction vessel yielding a constant solvent density of $0.16 \mathrm{~g} / \mathrm{ml}$ (500 $\mathrm{ml}$ vessel). After a reaction period of 0 to $8 \mathrm{~h}$ the vessel was rapidly cooled (10 - 30 ${ }^{\circ} \mathrm{C} / \mathrm{min}$ ) with ice, and the reaction period was defined to end when cooling was commenced. The final gas pressure was noted at ambient temperature after which gas was evacuated to a gas bag for further analysis. The contents of the batch autoclave were weighed and filtered on a pre-weighed filter. The filter cake comprising of the solid residual product of the solvolysis reaction was washed with an additional $25 \mathrm{ml}$ of fresh solvent and 
subsequently dried at $70^{\circ} \mathrm{C}$ for $72 \mathrm{~h}$ or until stable weight. The filtrate was rotary evaporated $\left(45^{\circ} \mathrm{C}, 5 \mathrm{mbar}\right)$ for $45 \mathrm{~min}$ or until stable weight of the heavy liquid fraction. The heavy fraction is denoted the oil product in this study and is assumed water free due to the severity of the evaporation. The oil is equally assumed ash free as a limited number of thermogravimetric analyses revealed less than $<0.2 \mathrm{wt} \%$ non-combustible residue. The water content in selected oils was determined by Karl Fischer titration and found to be of the order of 3-4 wt\%. Due to the high viscosity of the oils and low amounts recovered, an accurate determination of water content in all oils was not carried out (see also below under Analytical Procedure). The light fraction recovered after rotary evaporation comprises mainly of recovered ethanol and some light organics and reaction water. Both the oil and the light product obtained were subjected to further analyses.

\section{Solid yield.}

The yield of solid residual product was determined as the weight of dried isolated solid product relative to the weight of added lignin feedstock.

\section{Oil yield.}

The yield of oil product was determined as the weight of isolated heavy liquid product relative to the weight of added lignin feedstock. Yields can be expressed on a dry ash free basis (wt\%d.a.f.) relative to the mass of biomass (lignin) processed.

\section{Solvent consumption.}

GC-FID and Karl Fischer titration was used for the quantification of ethanol in the light fraction obtained after rotary evaporation. The solvent consumption is represented as the amount of solvent consumption/loss per amount of solvent added to the reaction vessel. The solvent consumption was determined as the difference between mass of ethanol after reaction and mass of ethanol solvent added prior to reaction. The quantified mass of ethanol in the isolated light 
fraction (water, solvent and other light organics) is lower than the mass of ethanol immediately after reaction due to handling losses. These losses are assumed solely to be light reaction products. Therefore the light fraction immediately after reaction equals the sum of handling loss and mass of isolated light fraction. Of this sum the amount of ethanol immediately after reaction is determined. The mass loss was determined as the difference between the weight of the nongaseous contents of the reaction vessel immediately after the reaction and the combined mass of isolated dry solid residual, heavy oil and light reaction products.

\section{Gas yield.}

The total gas yield was determined as the gauge pressure reading after cooling of the reaction vessel to room temperature. The analog pressure display goes to 344 bar and has an uncertainty of about \pm 0.5 bar. The gas composition was analyzed as described below under "Gas analysis".

\section{Analytical Procedure}

\section{Oil solubility in Heptane.}

Oil product (heavy liquid fraction) obtained in quantities greater than $2 \mathrm{~g}$ were subjected to a solubility test in heptane as a model solvent having similar properties to those of fossil diesel. $2 \mathrm{~g}$ or more of product oil were mixed in heptane in a 1:9 (w:w) ratio in an Eppendorf ${ }^{\mathrm{TM}}$ tube in duplicates. After mixing, the tube was centrifuged and the supernatant removed and placed in a separate tube. Both supernatant and insoluble fractions were evaporated under vacuum to remove heptane, and masses of the two fractions were determined. Solubility was determined as the weight of heptane solubilized oil relative to the initial weight of oil. 


\section{Gas analysis (GC-TCD).}

Detection and quantification of gas species was done by analyzing the gas phase after solvolysis using a calibrated Agilent Technologies 7890A GC-TCD with two separate sample loops with argon and helium as carrier gasses respectively. Gas sampling from the batch reactor was done using a gas bag, and injection was done using a pump with a fixed pressure. The argon loop was capable of separating $\mathrm{H}_{2}$ with 6 psi argon on a packed Haysep $\mathrm{Q}$ column and a packed $5 \mathrm{~A}$ column at $50^{\circ} \mathrm{C}$. The helium loop was capable of separating the gasses $\mathrm{CO}, \mathrm{CO}_{2}, \mathrm{~N}_{2}, \mathrm{O}_{2}, \mathrm{CH}_{4}, \mathrm{C}_{2} \mathrm{H}_{6}, \mathrm{C}_{2} \mathrm{H}_{4}, \mathrm{C}_{3} \mathrm{H}_{8}$ and $\mathrm{C}_{3} \mathrm{H}_{6}$ with 8 psi helium on a packed Haysep Q column and two packed $5 \mathrm{~A}$ columns at $50^{\circ} \mathrm{C}$. Total analysis time was $20 \mathrm{~min}$.

\section{GC-MS/FID.}

Analysis of the light liquid fraction obtained after rotary evaporation was analyzed by a Shimadzu GC-MS/FID-QP-2010UltraEi. The column was a Supelco Equity-5. Liquid samples were injected with a split ratio of $1: 80$ at $250^{\circ} \mathrm{C}$. The column was held at $40^{\circ} \mathrm{C}$ for $3 \mathrm{~min}$, heated to $100^{\circ} \mathrm{C}\left(2^{\circ} \mathrm{C} / \mathrm{min}\right)$, heated to $250^{\circ} \mathrm{C}\left(20^{\circ} \mathrm{C} / \mathrm{min}\right)$ and held for $2 \mathrm{~min}$ at $250^{\circ} \mathrm{C}$. A mass spectrometer using a scanning rate of $1666 \mathrm{~m} / \mathrm{z} / \mathrm{s}$ in the range $20-300 \mathrm{~m} / \mathrm{z}$ was used for the identification of light organic reaction products. A flame ionization detector was used for quantification of ethanol solvent. The area percent of the ethanol peak in the chromatogram was used to determine the ethanol percentage of the organic fraction. After quantification of the water content of the light fraction by Karl Fischer titration, the weight percent of ethanol in the light fraction was calculated as:

Eq. $1 \quad$ wt $\%$ ethanol $=(100-w t \%$ water $) / 100 \times$ area $\%$ ethanol 


\section{Karl Fischer Titration.}

The water content of light liquid fractions was quantified using a $701 \mathrm{KF}$ Titrino auto titrator with HYDRANAL®-Composite 5 (Sigma-Aldrich). A sample size of 1-2 ml was used and titration was repeated three times. Due to the high viscosity of the oils produced and the relatively low amounts recovered, an accurate determination of water content of all oils by Karl Fischer titration was difficult. Selected oils obtained as a result of treating $40 \mathrm{~g}$ of lignin in $100 \mathrm{ml}$ of ethanol were however analyzed yielding a water content of only 3-4 wt\% (see Supporting Information for more details). We expect the other oils to have similar low water contents.

\section{Elemental analysis (CHNS-O).}

Elemental analysis of solid and heavy liquid (oil) samples was performed using a Eurovector EA-3000 calibrated for C, H, N and S. Oxygen was determined by difference.

\section{Size Exclusion Chromatography.}

Size Exclusion Chromatography (SEC) was conducted on heavy liquid (oil) obtained in the experiments as well as the solid lignin rich feedstock. Size Exclusion Chromatography was performed with a $100 \AA$ A PolarSil column (Polymer Standard Service) at a column temperature of $40^{\circ} \mathrm{C}$ and flow rate of $1 \mathrm{~mL} / \mathrm{min}$. The eluent was a $0.05 \mathrm{M} \mathrm{LiBr}$ in 9:1 DMSO: $\mathrm{H}_{2} \mathrm{O}$ solution, which was also used as solvent for the bio-oil samples. One experiment lasted $15 \mathrm{~min}$. As standards, phenol $(\mathrm{Mw}=94 \mathrm{~g} / \mathrm{mol})$ and guaiacylglycerol-beta-guaiacyl ether $(\mathrm{Mw}=320 \mathrm{~g} / \mathrm{mol})$ were used as we find these standards to be more accurate than polymers (e.g. polystyrene) in this low Mw range.

\section{Solution state NMR spectroscopy.}

Solution state NMR spectroscopy was conducted on heavy liquid (oil) obtained in the experiments as well as the solid lignin rich feedstock. NMR-spectra were acquired using a 
$600 \mathrm{MHz}$ Bruker Avance III HD equipped with a cryogenically cooled $5 \mathrm{~mm}$ dual probe optimized for ${ }^{13} \mathrm{C}$ and ${ }^{1} \mathrm{H}$. Samples were dissolved in $600 \mu \mathrm{L}$ acetone- $d_{6}$ (Sigma-Aldrich, 99.9 atom \% D) (acetone was found to completely dissolve the bio-oils) and analyzed at $300 \mathrm{~K}$. For $1 \mathrm{D}{ }^{13} \mathrm{C}-\mathrm{NMR}$ a standard Bruker pulse sequence was applied and data processing was done in Bruker TopSpin. Calibration standard was acetone $\left({ }^{13} \mathrm{C}=29.84 \mathrm{ppm}\right)$. Integration was performed over the areas described in this paper with the exception of the area $0-60 \mathrm{ppm}$, where the intense acetone solvent peak (29.84 ppm) was omitted. For ${ }^{13} \mathrm{C}$ HSQC-NMR 16 scans of the Bruker pulse sequence hsqcetpg was applied with a fixed spectral width of $220 \mathrm{ppm}$ for ${ }^{13} \mathrm{C}$ and $13 \mathrm{ppm}$ for ${ }^{1} \mathrm{H}$. For ${ }^{13} \mathrm{C}$ HMBC-NMR 8 scans of the Bruker pulse sequence hmbcgpndqf was used with a fixed spectral width of $220 \mathrm{ppm}$ for ${ }^{13} \mathrm{C}$ and $13 \mathrm{ppm}$ for ${ }^{1} \mathrm{H}$. Lignin peak assignment was done according to a standard procedure $^{25}$, and spectra were colored in Adobe Illustrator.

\section{Solid State NMR.}

Solid-state NMR spectra were recorded at $296 \mathrm{~K}$ on a Bruker Avance 400 spectrometer operating at Larmor frequencies of $100.62,105.85$ and $400.13 \mathrm{MHz}$ for ${ }^{13} \mathrm{C},{ }^{23} \mathrm{Na}$ and ${ }^{1} \mathrm{H}$, respectively, using a double-tuned cross polarization (CP) magic angle spinning (MAS) probe equipped for $4 \mathrm{~mm}$ (o.d.) rotors. ${ }^{13} \mathrm{C}$ MAS spectra were recorded using a contact time of $1.0 \mathrm{~ms}$, a spin-rate of $13 \mathrm{kHz}$, a recycle delay of $2 \mathrm{~s}, 4096 \mathrm{scans}$, and an acquisition time of $30.6 \mathrm{~ms}$ during which ${ }^{1} \mathrm{H}$ TPPM decoupling ( $80 \mathrm{kHz}$ rf-field strength) was employed. ${ }^{26}$ For the SP/MAS spectra a recycle delay of $64 \mathrm{~s}$ and 1024 scans were used, whereas a recycle delay of $2 \mathrm{~s}, 4096$ scans and a contact time of $1 \mathrm{~ms}$ was employed for the CP/MAS spectra. The cross polarization was carried out using variable-amplitude $\mathrm{CP}^{27}$ with a maximum rffield strength of $80 \mathrm{kHz}$ for both ${ }^{1} \mathrm{H}$ and ${ }^{13} \mathrm{C} .{ }^{13} \mathrm{C}$ chemical shifts are referenced to an 
external sample of $\alpha$-glycine (carbonyl group) at $176.5 \mathrm{ppm}$. Single-pulse ${ }^{23 N a}$ MAS NMR spectra were recorded using a $1.8 \mu$ s pulse (69.4 kHz rf-field strength), spin-rate of $13 \mathrm{kHz}$, a recycle delay of $16 \mathrm{~s}, 1024$ scans, and an acquisition time of $40.9 \mathrm{~ms} .{ }^{23} \mathrm{Na}$ chemical shifts are referenced to an external sample of $1.0 \mathrm{M} \mathrm{NaCl}$ (aq).

\section{Results and discussion}

\section{Product Yields}

The main products of lignin solvolysis are oil, solid residual and gases. Oil, solid and gas yields of the solvolysis are shown together with solvent consumption as a function of reaction temperature, reaction period and amount of lignin added to the reaction vessel, see Figure 2. Compositional gas data is shown for the experimental series as a function of reaction time and degree of lignin loading, see Figure 3. Data from additional experimental series can be found in Supporting Information.

\section{Effect of reaction temperature on product yields.}

The effect of solvolysis temperature ranging from $250-450^{\circ} \mathrm{C}$ on the yields with $10 \mathrm{~g}$ lignin in $100 \mathrm{ml}$ ethanol at a reaction time of $4 \mathrm{~h}$ is seen in Figure 2a. An optimum oil yield of $0.4 \mathrm{~g} / \mathrm{g}$ lignin is observed around $400^{\circ} \mathrm{C}$. If the temperature is increased further, the final pressure after cooling of the vessel increases from 10 to 50 bar indicating a significant loss as light gases. The yield of oil and solid residual product is approximately $80 \%$ of the initial lignin feed for temperatures up to $400^{\circ} \mathrm{C}$, but at $450^{\circ} \mathrm{C}$ there is a drop to approximately $60 \%$, indicating that at least $20 \%$ of the lignin is gasified. The sharp increase in gas formation suggests, that the pathway for lignin depolymerization and decomposition is dominated by simple thermal breakage of lignin interlinkages to light species. Lee and Lee ${ }^{17}$ conducted thermal cracking of Kraft lignin in n-butanol from $250^{\circ} \mathrm{C}$ to $450^{\circ} \mathrm{C}$ and 
equally found an optimum temperature of $400^{\circ} \mathrm{C}$ with respect to maximizing the degree of lignin conversion determined by the amount of residual solid; however, at higher temperatures the conversion levelled off contrary to the observation herein. The majority of studies on lignin solvolysis by alcohols typically investigate temperatures below $400^{\circ} \mathrm{C} .4$, ${ }^{28} \mathrm{Kim}$ et al. ${ }^{18}$ found an optimum oil yield of $95 \mathrm{wt} \%$ from organosolv lignin solvolysis in ethanol at only $200^{\circ} \mathrm{C}$ for temperatures up to $350^{\circ} \mathrm{C}$ tested, but the oil product was substantially less depolymerized at the lower temperature $(\sim 2500 \mathrm{~g} / \mathrm{mol})$ relative to higher temperature $(\sim 800 \mathrm{~g} / \mathrm{mol})$.

Solvent consumption as a function of reaction temperature shows a minor increase from $10 \mathrm{wt} \%$ at $250^{\circ} \mathrm{C}$ and $300^{\circ} \mathrm{C}$ to $18 \mathrm{wt} \%$ at $350^{\circ} \mathrm{C}$. When the temperature is increased further from $400^{\circ} \mathrm{C}$ to $450^{\circ} \mathrm{C}$ the solvent consumption increases two-fold from $35 \mathrm{wt} \%$ to $77 \mathrm{wt} \%$ (see Figure 2a). The results show that despite a higher oil yield at $400^{\circ} \mathrm{C}$ it can be advantageous to conduct the process at lower temperatures in order to reduce solvent consumption.

\section{Effect of reaction time on product yields.}

The effect of reaction time on yields of lignin solvolysis is shown for a reaction temperature of $400^{\circ} \mathrm{C}$ with $10 \mathrm{~g}$ lignin in $100 \mathrm{ml}$ ethanol (Figure $2 \mathrm{~b}$ ). The oil yield increases from $0.28 \mathrm{~g} / \mathrm{g}$ lignin after $0 \mathrm{~h}$ (i.e. heating to the reaction temperature followed by immediate cooling) to $0.42 \mathrm{~g} / \mathrm{g}$ lignin (50 wt\%d.a.f.) after $8 \mathrm{~h}$ with only a minor increase in oil yield when the reaction is extended from 4 to $8 \mathrm{~h}$.

Gaseous reaction products were continuously formed for all experiments at $300^{\circ} \mathrm{C}$ and higher. For the reaction temperature of $400^{\circ} \mathrm{C}$ the gas yield increases proportionally as a function of reaction time up to $8 \mathrm{~h}$ (Figure $2 \mathrm{~b}$ ). The yield of oil plus solid residual equally 
increased as a function of reaction time. Therefore, the additional amount of gas formed over time must primarily come from solvent decomposition. The solvent consumption equally exhibits a linear increase as a function of reaction time. The solvent is consumed at a rate of $2.6 \mathrm{~g} / \mathrm{h}$ which exceeds the rate at which additional oil is produced at an average of $\sim 0.20 \mathrm{~g} / \mathrm{h}$ by more than tenfold (linear fits are shown in Supporting Information). A zeroth order reaction of solvent degradation is thus inevitable.

Propene and propane comprise the smallest percentage of gasses formed ( $<4 \mathrm{vol} \%)$ (see Figure 3a). The saturated hydrocarbon gas species comprising propane, ethane and methane increase faster as a function of time relative to their unsaturated counterparts (propene and ethene). The yield of ethane and methane increases faster than the yield of $\mathrm{CO}$ and $\mathrm{CO}_{2}$, which shows a disadvantageous effect of longer residence time for optimizing the degree of lignin deoxygenation.

\section{Effect of lignin loading on product yield.}

For what seems to be an optimum temperature in order to maximize oil yield at $400^{\circ} \mathrm{C}$, a series of experiments were conducted at this temperature with varying degrees of lignin:solvent ratio and a fixed reaction time of $4 \mathrm{~h}$ (see Figure 2c). The high lignin to solvent loading of up to $40 \mathrm{~g}$ lignin in $100 \mathrm{ml}$ ethanol resulted in a mixture with a surprisingly low viscosity that was easy to handle. Such a high lignin loading is substantially higher than previously reported values. ${ }^{14,}$ 18-23 There are few studies that investigate the effects of different lignin to alcohol ratios $7,18,29$, and a comparison is difficult due to differences in lignin feedstock, alcohol and reaction parameters.

The oil yield decreases when the lignin loading is increased, and the yield of solid residual correspondingly increases. This was equally observed for all temperatures 
between $250^{\circ} \mathrm{C}$ and $450^{\circ} \mathrm{C}$ (see Supporting Information). This effect is expected due to increased repolymerization from a $2^{\text {nd }}$ order reaction, as the lignin concentration is increased at high lignin loading. However, it poses other questions whether the lignin solvolysis is limited by a maximum solubility effect in ethanol and/or simply varying degrees of mixing in the reaction vessel.

Reduced mixing at higher degrees of lignin loading was visually confirmed upon opening of the vessel after cooling. For all lignin loadings tested, a clear line of char was visible only on the inside wall of the liner. This was more pronounced for a loading of $20 \mathrm{~g}$ and $40 \mathrm{~g}$ lignin, where char formed was harder to remove as it condensed on the inside of the liner. These observations indicate that during reaction, the re-polymerization products (char) are formed and kept only within the liner, hence they are insoluble in supercritical ethanol. Upon opening of the vessel condensed clear liquid, mainly comprising of solvent, was found in the narrow space occupied between the outside of the liner wall and the reactor vessel wall. The filtrate upon isolating the solids from the liquid phase inside the liner prior to analysis is pitch black, indicating that liquid condensed on the outside of the liner did not contain noticeable amounts of depolymerized lignin species/oil. This highlights a potentially important discovery that both lignin and bio-oil are not dissolved in the supercritical ethanol at reaction conditions. Instead a distinct lignin phase occupies the bottom of the vessel, and a lower relative ethanol concentration in this phase may be responsible for differences in oil and gas yields and solvent consumption when the loading of lignin is increased. Soria et al. ${ }^{30,} 31$ found for pine wood solvolysis in supercritical methanol that a high solvent to vessel loading $(0.46 \mathrm{~g} / \mathrm{ml})$ ensures near complete liquefaction $(98 \%)$ at even the very high temperature of $500^{\circ} \mathrm{C}$. The low density of the 
supercritical ethanol $(0.16 \mathrm{~g} / \mathrm{ml})$ herein may be responsible for the insolubility of large depolymerized lignin fragments affecting the mechanism of the solvolysis. Hydrolysis lignin may also be less soluble in supercritical ethanol due to increased repolymerization from pretreatment ${ }^{32}$ compared to solvolysis of unprocessed woody biomass.

Strikingly more gas is formed with no lignin addition (i.e. only solvent) compared to adding 2 - 5 g lignin. This indicates an effect by which lignin inhibits ethanol to gas decomposition. At higher degrees of lignin loading the final gas pressure proportionally follows the amount of lignin added, indicating that the majority of gaseous species formed comes from lignin. Lignin is increasingly decomposed to gasses as a function of lignin loading as the sum of solid residual and oil product decreases.

Solvent consumption per solvent added increases with increased lignin loading, indicating that solvent is lost due to a reaction in the presence of lignin and a $40 \mathrm{~g}$ lignin loading results in $60 \mathrm{wt} \%$ solvent consumption.

Gaseous hydrocarbons such as ethane and methane are formed even in the case of no lignin addition (see Figure 3b), hence these are products of solvent decomposition. The yield of all gaseous hydrocarbons is however strikingly proportional to the amount of lignin added. In particular ethane and methane yields increase at the same rate and in near identical quantities. Gaseous hydrocarbons may be formed as a direct lignin breakdown product, as the methoxy functionalities in the lignin are converted to methane. Different breakdown reactions of the phenyl propane monomers may yield ethane and propane. On the other hand, the presence of lignin in supercritical ethanol could also facilitate solvent decomposition to gas. Zhao et al. ${ }^{7}$ proposed a mechanism in which thermally induced homolytic cleavage of supercritical ethanol forms ethyl radicals that facilitate the cleavage 
of the lignin polymer and is simultaneously incorporated into the depolymerized lignin. Such incorporation of the solvent ethanol into the depolymerized lignin structure, and a subsequent thermally induced bond cleavage, may ultimately yield ethane gas. Here we find that ethene and propene levels are nearly unchanged relative to the yields of ethane and propane respectively, showing that the former likely are products of solvent decomposition only.

When no lignin is added the $\mathrm{CO}_{2}$ yield is near zero, and it increases linearly with lignin addition (see Figure $3 \mathrm{~b}$ ). This shows that $\mathrm{CO}_{2}$ is mainly a product of lignin deoxygenation likely through decarboxylation. In one experiment where $40 \mathrm{~g}$ lignin was treated at $350^{\circ} \mathrm{C}$ for $2 \mathrm{~h}$, the formed $\mathrm{CO}_{2}$ comprised more than $50 \mathrm{vol} \%$ of all of the gasses formed (experimental data is supplied in Supporting Information). This accounts for $18 \mathrm{wt} \%$ of the oxygen initially present in the lignin. At a reaction time of $4 \mathrm{~h}$ and a temperature of $400^{\circ} \mathrm{C}$ the oxygen removal by $\mathrm{CO}_{2}$ increased to $34 \mathrm{wt} \%$. The water gas shift reaction (see Eq. 2) has a negligible influence on the high $\mathrm{CO}_{2}$ yield as the reaction is far from equilibrium with a reaction constant that is a factor $10^{2}$ to $10^{3}$ smaller than the equilibrium constant for the water gas shift reaction at $400^{\circ} \mathrm{C}$ (data for calculation is supplied in Supporting Information).

Eq. $2 \mathrm{H}_{2} \mathrm{O}+\mathrm{CO} \rightleftharpoons \mathrm{H}_{2}+\mathrm{CO}_{2}$

The amount of water formed also increases as a function of lignin addition (supplied in Supporting Information); however, when lignin addition increases from 20 to $40 \mathrm{~g}$ the rate of water formation is slightly decreased. 
The CO yield is nearly constant as a function of lignin loading showing that this gas species is mainly a product of ethanol decomposition. $\mathrm{CO}, \mathrm{CH}_{4}$ and $\mathrm{H}_{2}$ are also expected reaction products of ethanol decomposition at elevated temperatures. ${ }^{33}$

The absolute hydrogen yield is low and increases only very little from 1 bar (9.7 vol\%) with no lignin addition to 3 bar (6.9 vol\%) with $40 \mathrm{~g}$ lignin addition. As hydrogen is highly reactive at the experimental conditions, it can only be concluded that hydrogen is a thermal breakdown product of alcohol and lignin.

\section{Oil Product Analysis}

It is desired to reduce the oxygen content of the product oil as much as possible as a low oxygen content yields a higher heating value of the lignin-oil. For fuel applications of the lignin oil where blending with a fossil fuel is required, a lowering of the oxygen content also reduces the polarity and hence increases the miscibility. Low oxygen content in the product oil also has benefits including reduced reactivity and higher stability of the oil product. Especially carbonyl functionalities in the oil are believed to cause polymerization reactions. ${ }^{34}$ None of the lignin oils obtained in this study had a, by NMR, detectable aldehyde or ketone content (see Figure 4). This corresponds well with the fact that, neither formation of sediments nor a change in molecular size distribution was detected in oils stored at room temperature for 11 months (see Supporting Information). ${ }^{13} \mathrm{C}-\mathrm{HMBC}$ NMR spectra also showed no detectable amount of aldehydes and carboxylic acids in any of the lignin oils obtained (see Supporting Information). This is a highly desirable property, as it reduces the potential for polymerization, and a low acidity is required for fuels used in internal combustion engines. The oils obtained by solvolysis are of better quality than 
pyrolysis oils, as the latter are acidic and readily polymerize due to oxygen functionalities. The esters in the oil fraction show a way in which lack of acidity is obtained from condensation between carboxylic acids and alcohols. ${ }^{13} \mathrm{C}-\mathrm{HSQC}$ NMR analysis was carried out for the lignin starting material (the NMR data on the lignin starting material shows that it is identical to previous reports on lignin in hydrothermally pretreated wheat straw ${ }^{35}$ ) as well as oils obtained by solvolysis at all temperatures (spectra are supplied in Supporting Information). For all of the oils obtained ${ }^{13} \mathrm{C}-\mathrm{HSQC}$ NMR spectra show a complete removal of carbohydrates that are present in the lignin feedstock. The lignin unit linkages such as $\beta$ $0-4, \beta-5$ and $\beta-\beta$ identified in the lignin feedstock are broken at all temperatures tested in the ethanol solvolysis. The lignin feedstock is composed of syringyl (S) and guaiacyl (G) units with no noticeable amount of p-hydroxyphenyl $(\mathrm{H})$ units. The lignin-oilcontains a narrow aromatic region showing a reduction in substituents on the aromatic rings and no noticeable S units.

In the following the oil product is analyzed and discussed in regards to oxygen content (Figure 5), molecular size distribution by SEC (Figure 6) and composition by ${ }^{13} \mathrm{C}$ NMR (Figure 4). Data from additional experimental series is supplied in Supporting

\section{Information.}

\section{Effect of reaction temperature on oil quality.}

The lignin feedstock has a molar $\mathrm{O} / \mathrm{C}$ ratio of 0.4 , thus a reduction in oxygen content for all reaction temperatures is obtained (see Figure 5a). An increase in temperature increases the degree of deoxygenation which corresponds well with a lower bond enthalpy for oxygen functionalities and linkages than for C-C bonds. ${ }^{36}$ Solvolysis at $450^{\circ} \mathrm{C}$ yielded an oil product with a molar $0 / \mathrm{C}$ of 0.12 . 
When the reaction temperature increases, the molecular size distribution in the oil product mixture narrows. The products are similar in size to lignin monomers (see Figure 6a). At $250^{\circ} \mathrm{C}$ and $300^{\circ} \mathrm{C}$ specifically there is a shoulder in the molecular size distribution curves. This indicaes a heterogeneous mixture with the majority of species having a molecular weight larger than $320 \mathrm{~g} / \mathrm{mol}$ i.e. a mixture dominated by lignin dimers and larger products. At these lower reaction temperatures, the oils were by observation substantially more viscous than those obtained at higher temperatures. Oxygen removal at elevated temperatures corresponds well with ${ }^{13} \mathrm{C}$ NMR of the product oil (see Figure 4a), where the aliphatic oxygenated region ( $\mathrm{sp}^{3}$ oxygenated) is reduced as a function of reaction temperature. NMR data on the oil product further shows that, the ratio between the nonoxygenated aliphatic and aromatic fractions is hardly changed in the temperature range from $250^{\circ} \mathrm{C}$ to $350^{\circ} \mathrm{C}$. As the temperature increases to $400^{\circ} \mathrm{C}$, the oxygen content is further reduced, and the deoxygenated aliphatic fraction increases. The aromatic fraction is nearly unchanged up to $400^{\circ} \mathrm{C}$, which is also seen from the near constant molar $\mathrm{H} / \mathrm{C}$ ratio (see Figure 5a). At a reaction temperature of $450^{\circ} \mathrm{C}$, the oxygenated fraction is almost fully reduced, and the unsaturated fraction is increased resulting in a drop in molar $\mathrm{H} / \mathrm{C}$ ratio from 1.5 to 1.3 . At $450^{\circ} \mathrm{C}$ there is an increased degree of gas formation directly stemming from the lignin (see Figure 2a), and the oil yield is reduced by around 50\% while the solid residual yield remains unchanged. This observation together with the near doubling in relative aromatic content indicates that, an increasing proportion of aliphatic functionalities in the oil fraction are transformed to gas at $450^{\circ} \mathrm{C}$.

Using an empirical correlation ${ }^{37}$ and the elemental composition of the oil the higher heating value (HHV) can be estimated. At $400^{\circ} \mathrm{C}$ the oil product has a higher heating value 
of $35 \mathrm{MJ} / \mathrm{kg}$ which corresponds to an energy recovery yield of $70 \%$ (relative to the higher heating value of the lignin rich solid feedstock). At $450^{\circ} \mathrm{C}$ the combined effect of both reduced molar $\mathrm{O} / \mathrm{C}$ and reduced molar $\mathrm{H} / \mathrm{C}$ of the oil results in an unchanged $\mathrm{HHV}$ of the oil product and the reduced oil yield therefore results in an energy recovery of only $36 \%$. In particular the substantial increase in solvent consumption when the temperature is increased from $400^{\circ} \mathrm{C}$ to $450^{\circ} \mathrm{C}$ further emphasizes that an optimum reaction temperature is lower than $450^{\circ} \mathrm{C}$.

\section{Effect of lignin loading on oil quality.}

The molar $0 / \mathrm{C}$ ratio is reduced at increased lignin loading at $400^{\circ} \mathrm{C}$ (see Figure $5 \mathrm{c}$ ). A reduction in molar $\mathrm{O} / \mathrm{C}$ ratio was equally observed at increased loading for all temperatures (see Supporting Information).

At the highest degree of lignin loading the molar 0/C ratio was lowered to 0.09 or an oxygen content of $9.7 \mathrm{wt} \%$. This corresponds to a higher heating value of the oil of 38 $\mathrm{MJ} / \mathrm{kg}$ (calculated using elemental composition and an empirical correlation from Parikh et al. $^{37}$ Such a high degree of deoxygenation has not previously been reported on liquefaction of lignin by non-catalytic means and without a reducing agent such as hydrogen. The oil yield decreases faster than the drop in oxygen content at increased lignin loading, suggesting increased re-polymerization.

${ }^{13} \mathrm{C}$ NMR of the resulting oils clearly shows an increased oxygen removal from $\mathrm{sp}^{3}$ carbon as a function of loading (see Figure 4c). The aromatic fraction of the oil increases when the lignin loading is increased from $2 \mathrm{~g}$ to $5 \mathrm{~g}$ after which the aromaticity barely changes; however, the highest degree of aromaticity is found for the highest lignin loading. The molar $\mathrm{H} / \mathrm{C}$ ratio, shown as a function of lignin loading (see Figure $5 \mathrm{c}$ ), equally shows a near 
constant value of 1.5 going from $5 \mathrm{~g}$ to $40 \mathrm{~g}$ loading and a slightly higher value of around 1.6 at $2 \mathrm{~g}$ loading. This combined with the higher oil yield at the lowest lignin loading indicates that a fraction of the oil is polymerization products of the solvent ethanol.

At $400^{\circ} \mathrm{C}$ the molecular size distribution becomes narrower and shifts towards smaller molecular size species for increasing lignin loading (see Figure 6c). This was equally observed at $300^{\circ} \mathrm{C}$ (see Supporting Information). A high degree of lignin loading is thus beneficial with respect to both obtaining a deoxygenated oil product and reduced molecular size.

Increased lignin loading results in locally ethanol starved regions due to reduced mixing, and especially at the bottom of the reaction vessel where undissolved lignin fragments displace the ethanol. This results in reduced interaction between solvent and lignin. Regardless, the resulting oil product in this study is inherently different and of better quality than pyrolysis oil.

\section{Effect of reaction time on oil quality.}

For up to $8 \mathrm{~h}$ reaction time the molar $\mathrm{O} / \mathrm{C}$ in the obtained oil product is fairly uniform at around 1.5 for a reaction temperature of $400^{\circ} \mathrm{C}$ and $10 \mathrm{~g}$ lignin loading (see Figure $5 \mathrm{~b}$ ). The molar $\mathrm{H} / \mathrm{C}$ in the oil increases from 1.44 to 1.57 going from 0 to $8 \mathrm{~h}$ reaction time indicating a decrease in the aromaticity. This decrease in aromaticity corresponds to a reduction in relative aromatic carbon atoms by one third (see Figure $4 \mathrm{~b}$ ). The molecular size distribution of the oil becomes increasingly narrow and shifts towards smaller molecular size species below $320 \mathrm{~g} / \mathrm{mol}$ after $8 \mathrm{~h}$ (see Figure 6b). In conjunction with increased oil yield this shows that the relative increase in aliphatics over time in the oil is not due to an 
increase in aliphatics attached to aromatic oil species, as the SEC data only represents aromatic molecules. This is likely arising from irreversible solvent reactions.

\section{Miscibility with heptane.}

An advantage of low oxygen content in the oil is the increased miscibility with a nonpolar fossil diesel. The target of this study was to produce a lignin-oil that would satisfy fuel standards for use in engines tolerating more crude fuels (e.g. marine engines) and successfully blend with a fossil diesel. The molar $\mathrm{O} / \mathrm{C}$ also serves as a benchmark for the oil quality as can be seen in Figure 7, where the solubility in heptane as a function of molar O/C for select oils is represented. Heptane was used as a substitute for fossil diesel possibly representing an even more non-polar substance due to the lack of aromatics. As the molar $\mathrm{O} / \mathrm{C}$ is reduced to near 0.1 , the solubility approaches $80 \%$ thus showing that exhaustive deoxygenation is not needed.

\section{Residual Solid Product Analysis}

The residual solid product of the solvolysis is a potentially valuable by-product. This biochar can be put back into the soil from where the biomass was harvested, which may improve soil quality. ${ }^{38}$ Alternatively the biochar can be burned in a power plant as a coal substitute.

Figure 8 shows the ${ }^{13} \mathrm{C}$ and ${ }^{23} \mathrm{Na}$ solid-state MAS NMR spectra for residual solid obtained at solvolysis temperatures of $250^{\circ} \mathrm{C}$ to $450^{\circ} \mathrm{C}$. Three different types of solid-state MAS NMR spectra were recorded: ${ }^{13} \mathrm{C} \mathrm{CP} / \mathrm{MAS},{ }^{13} \mathrm{C}$ SP/MAS and ${ }^{23} \mathrm{Na}$ SP/MAS. In the ${ }^{13} \mathrm{C} \mathrm{CP} / \mathrm{MAS}$ NMR spectra the intensity of carbon sites situated in immobile regions of the sample are enhanced whereas the carbon sites are recorded in a quantitative manner by the ${ }^{13} \mathrm{C}$ 
SP/MAS NMR experiments. The ${ }^{23} \mathrm{Na}$ SP/MAS NMR were also quantitative. A full description of the solid state NMR data on the lignin rich starting material is supplied in Supporting Information together with data on the solid residual obtained from the experimental series with varying reaction time and lignin loading.

The ${ }^{23} \mathrm{Na}$ SP/MAS spectrum for lignin shows an almost featureless Lorentzian line shape which shows that sodium is located in a disordered environment. In the ${ }^{13} \mathrm{C}$ spectra it is seen that there is a dramatic change in the residual solid char structure when heating the biomass in ethanol. Upon heating to $250^{\circ} \mathrm{C}$, it was noted that lipids were removed and the carbohydrate content reduced. In addition the amount of etherified C3 and C5 in S units (syringyl) was significantly reduced whereas the non-etherified C3 and C5 in H units ( $p$ hydroxyphenyl) as well as C1 and C4 in G units (guaiacyl) were still observable. The aliphatics were also modified as seen by the appearance of two intense resonances at 15.0 and $30.4 \mathrm{ppm}$ indicating formation of saturated aliphatics. Judging by the intense resonance of the methyl groups $(15.0 \mathrm{ppm})$, the aliphatics are either short or highly branched. The applied lignin has been pretreated at $190^{\circ} \mathrm{C}$ during the $2^{\text {nd }}$ Generation bioethanol process, why a lot of structural change has already taken place and treatment in ethanol at $250^{\circ} \mathrm{C}$ is not severe enough to impose further structural changes to the majority of the lignin matrix. One could describe the solvolysis at $250^{\circ} \mathrm{C}$ more as an organosolv type process. As the reaction temperature is increased, the oxygenated part of the biomass is greatly reduced, and already at $300^{\circ} \mathrm{C}$, there is a clear reduction of carbohydrates and oxidized sp $\mathrm{s}^{3}$ carbons between 60 and $107 \mathrm{ppm}$ as well as for the methoxy resonance $\sim 56$ ppm. The distinct syringyl/guaiacyl resonances $\sim 150 \mathrm{ppm}$ were also reduced in this process. At a reaction temperature of $350^{\circ} \mathrm{C}$ the oxygenated fraction is completely gone, 
and the aromatic resonances are starting to become uniformly centered at $127 \mathrm{ppm}$. As the temperature reaches $400^{\circ} \mathrm{C}$, the aliphatic part of the biomass decreases dramatically, and at $450^{\circ} \mathrm{C}$ it is almost completely gone, leaving only a highly uniform aromatic part of the solid residual. This suggests that the solid residual char is mostly a polyaromatic hydrocarbon (PAH). By the ${ }^{23} \mathrm{Na}$ SP/MAS spectra it is observed that the sodium changes from a disordered environment in the lignin via an intermediate stage, having either a larger chemical shift distribution or sites with larger quadrupolar interactions at $250-300^{\circ} \mathrm{C}$ to a more ordered environment at higher temperatures. This is demonstrated by the presence of a second order quadrupolar line shape in the solid residual produced at $350^{\circ} \mathrm{C}$ and even more pronounced at $400^{\circ} \mathrm{C}$. It is anticipated that sodium is present in hydrated silicates and that $\mathrm{Na}^{+}$is coordinated to crystal water as well as oxygens from the silica. By increasing the temperature water is evaporated from the sample and therefore sodium is primarily coordinated to oxygens in silicates at higher temperatures. The ${ }^{23} \mathrm{Na}$ SP/MAS ordered part of the spectra resemble spectra of layered hydrous silicates and could potentially contain silicate structures similar to kanemite and octosilicates. ${ }^{39}$ One of the characteristics of octosilicates is that the chemical shift is lower for dry samples and that is what is observed in the spectra of the solid products at $350{ }^{\circ} \mathrm{C}$ and above. When water is removed from the sodium coordination will primarily be to oxygens from silicates. Comparison with ${ }^{23} \mathrm{Na}$ MAS NMR spectra of sodium silicate glasses ${ }^{40}$ indicates that the sodium silicate structure is primarily disordered.

For changes in reaction time of the lignin solvolysis the solid residual composition is seemingly unchanged even at an extended reaction time of $8 \mathrm{~h}$ (full solid state NMR spectral data as a function of reaction time is shown in Supporting Information). This shows 
that a state of equilibrium is reached at or before two hours of reaction time at the reaction temperature of $400^{\circ} \mathrm{C}$. It further supports, that a long reaction time is not advantageous for the liquefaction of lignin by ethanol, as a longer reaction time mostly contributes to solvent loss/consumption. In the ${ }^{23} \mathrm{Na}$ MAS NMR spectra substantial changes as a function of reaction time are observed. At $2 \mathrm{~h}$ the sodium in the ordered environment (second order line shape) most likely originating from the layered hydrous silicates dominates, whereas the sodium in less ordered (narrow line around $-10 \mathrm{ppm}$ ) environments are more pronounced after $8 \mathrm{~h}$ of reaction due to less water in the sample.

For changes in lignin loading between $10 \mathrm{~g}$ and $40 \mathrm{~g}$ lignin the carbon species of the solid residual is almost unchanged, as was also observed for the samples exposed to different reaction times at $400^{\circ} \mathrm{C}$ (full solid state NMR spectral data as a function of lignin loading is shown in Supporting Information). This indicates, that there is an energy activation barrier that needs to be overcome, before the biomass decomposes further. All of the solid residual obtained was, however, subjected to a reaction time of $4 \mathrm{~h}$, which means that differences in composition, due to varying degrees of lignin loading at shorter reaction times, may still exist. It seems as reaction temperature is the only parameter that substantially changes the composition of the organic fraction of the solid residual. The ${ }^{23} \mathrm{Na}$ NMR spectra changes towards a single sharp peak at increased loading. A plausible explanation for this could be that water is more efficiently removed from the sample at higher loading and therefore drives the Na coordination towards silicate oxygens.

Both higher loadings and longer reaction times promote formation of the disordered (sharp peak) sodium environment. It was observed that the spectrum of solid residual from solvolysis of $10 \mathrm{~g}$ lignin for $8 \mathrm{~h}$ at $400^{\circ} \mathrm{C}$ is similar to the spectrum of solids from 
solvolysis of $20 \mathrm{~g}$ lignin for $4 \mathrm{~h}$ at $400^{\circ} \mathrm{C}$, even though slightly more disordered sodium was observed in the latter.

Since an increase in lignin loading yields more solid residual with similar composition the additionally formed char must stem from a similar process/reaction as char formed at lower loadings. The majority of solid residual char is a direct result of lignin polymerization reactions, which occur to a greater extent when the "local" ethanol concentration and availability near depolymerized lignin species is lower and hence the potential for inhibiting repolymerization is lower.

\section{Discussion on Process Economy}

The conversion of solid lignin to a partially deoxygenated oil product represents a conversion from a solid fuel to a liquid fuel. With the current prices for solid and liquid fuels we estimate that the price for the lignin rich feedstock is around $2.5 \mathrm{USD} / \mathrm{GJ}$ and the oil product substituting a diesel is around 12 USD/GJ. The conversion thus represents a five-fold value increase on an energy basis, but with an increased energy density of the product oil the value increase on a mass basis approaches ten-fold since the heating value is doubled. The current price of ethanol is similar to the price of diesel oil which renders the process obviously economically unfeasible if more solvent ethanol is consumed than oil produced. A conversion of ethanol to gasses or light organic condensation products (i.e. higher alcohols and light ethers, esters and their fragmentation products) provides no value and is therefore highly disadvantageous whereas the conversion of ethanol to oil product by direct incorporation with depolymerized lignin fragments (i.e. ethylation or ethoxylation) will be generally more tolerable. By assuming that only the diesel miscible 
fraction of the oil can substitute a diesel then as a minimum, neglecting cost of plant operation and CAPEX, the following equation needs to be satisfied to achieve economic feasibility:

$1<\frac{\text { mass of oil produced }}{\text { mass of ethanol lost }}$ fraction of diesel miscible oil

In our small scale batch experiments the solvent loss due to handling resulted in a mass of lost ethanol exceeding the mass of oil produced; however, assuming complete mass balance closure the process may be economically feasible if solvent consumption is minimized corresponding to conditions with high degree of lignin loading, moderate reaction temperature likely no higher than $350{ }^{\circ} \mathrm{C}$ and reduced reaction time. These considerations are also discussed in greater detail in a simplified economic evaluation by Nielsen ${ }^{41}$. These reaction parameters are likely improved on a continuous setup, rather than the batch setup used herein, and we are therefore currently investigating the effects of continuous operation.

\section{Conclusions}

Batch autoclave experiments have shown that simple non-catalytic solvolysis of biorefinery lignin in supercritical ethanol can produce a heptane soluble bio-oil without the need for addition of catalyst or a reducing agent such as hydrogen.

In contrast to pyrolysis without a catalyst all of the oils obtained by ethanol solvolysis were acid free with no detectable carbonyl functionalities. This explains the high shelf stability (11 months) with neither sedimentation nor change in molecular size distribution. 
The solid residual char product has reduced oxygen content relative to the lignin feed making it a candidate for use as a biochar.

Decarboxylation is likely the main contributor to the lignin deoxygenation as the majority of $\mathrm{CO}_{2}$ formed comes from the lignin. $\mathrm{CO}$ was mainly the result of ethanol decomposition. Ethanol inhibits the repolymerization of depolymerized lignin species; however, reactions in which the solvent alcohol actively facilitates cleavage and becomes incorporated into the final oil product can also be argued, and most likely both kinds of reactions take place.

An oil yield of $0.4 \mathrm{~g} / \mathrm{g}$ lignin was obtained for solvolysis of $10 \mathrm{~g}$ lignin for $4 \mathrm{~h}$ at $400^{\circ} \mathrm{C}$ but deoxygenation results in a high energy recovery of $70 \%$ in the oil (relative to the $\mathrm{HHV}$ of the lignin rich solid feedstock); however, solvent consumption was high at $35 \mathrm{wt} \%$. A lower reaction temperature of $350^{\circ} \mathrm{C}$ may be advantageous as the solvent consumption is reduced by half.

We found that an increased lignin to ethanol ratio of up to $1: 2$ (w:w) resulted in an increasingly deoxygenated and depolymerized oil product. This highlights a new and previously unreported domain for lignin solvolysis. At the highest loading the resulting oil product had a very low molar 0/C ratio of 0.09 (corresponding to a $\mathrm{HHV}$ of $36 \mathrm{MJ} / \mathrm{kg}$ ) and size distribution dominated by mono- and dimer lignin species $(<300 \mathrm{~g} / \mathrm{mol})$; however, the oil yield was also reduced highlighting a trade-off between oil quality and yield.

The solvolysis was advantageously carried out with a low reaction time $(<1 \mathrm{~h})$ in order to limit solvent consumption.

The study herein provides a simplified approach which highlights that the key challenges of lignin solvolysis are lignin liquefaction yield versus solvent consumption. Thus the conventional approach involving maximization of depolymerization while minimizing 
repolymerization is of less importance. Further insights into the mechanisms of solvent consumption are required for development of lignin processing by solvolysis.. 


\section{FIGURES}

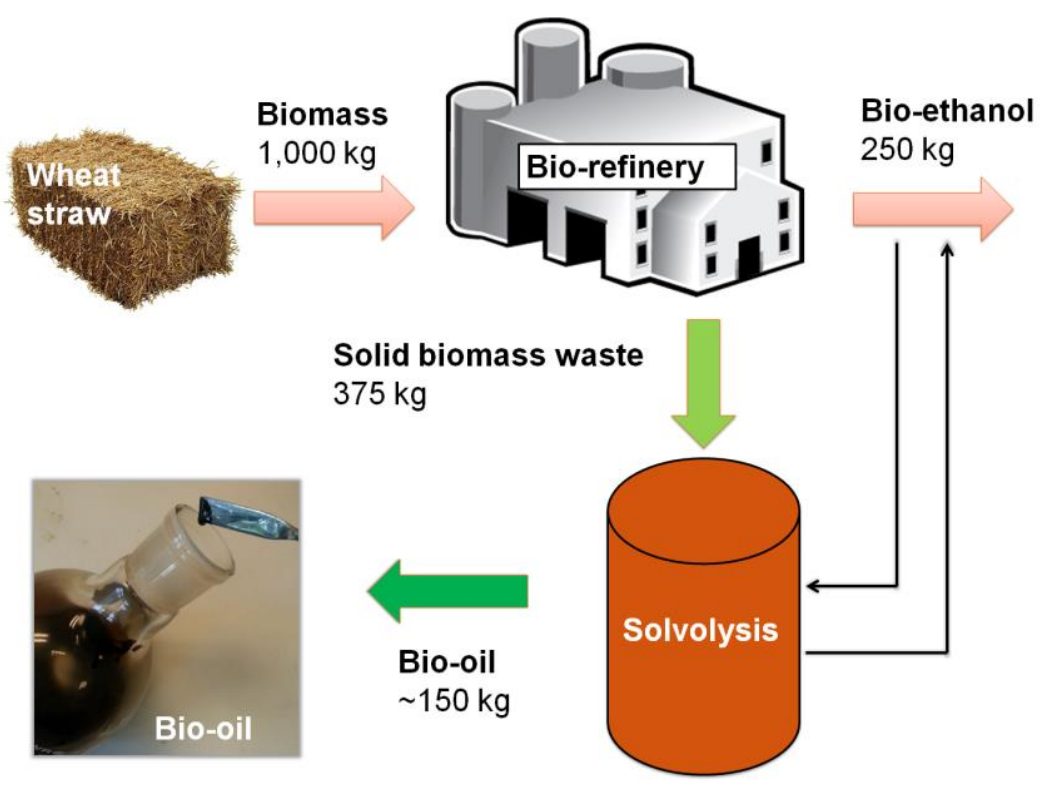

Figure 1. Integration of the ethanol solvolysis process in a bio-refinery concept with typical yields from processing $1,000 \mathrm{~kg}$ wheat straw. Waste streams such as water, gas and biochar have been omitted for simplicity. The bio-oil product depicted is the actual product of this study. The amount of ethanol recycled exceeds the amount produced and therefore a surplus of ethanol needs to be initially available on site. In this scenario the process can run indefinitely as long as no more than $250 \mathrm{~kg}$ of ethanol is lost per $375 \mathrm{~kg}$ of lignin rich solid biomass waste processed. 

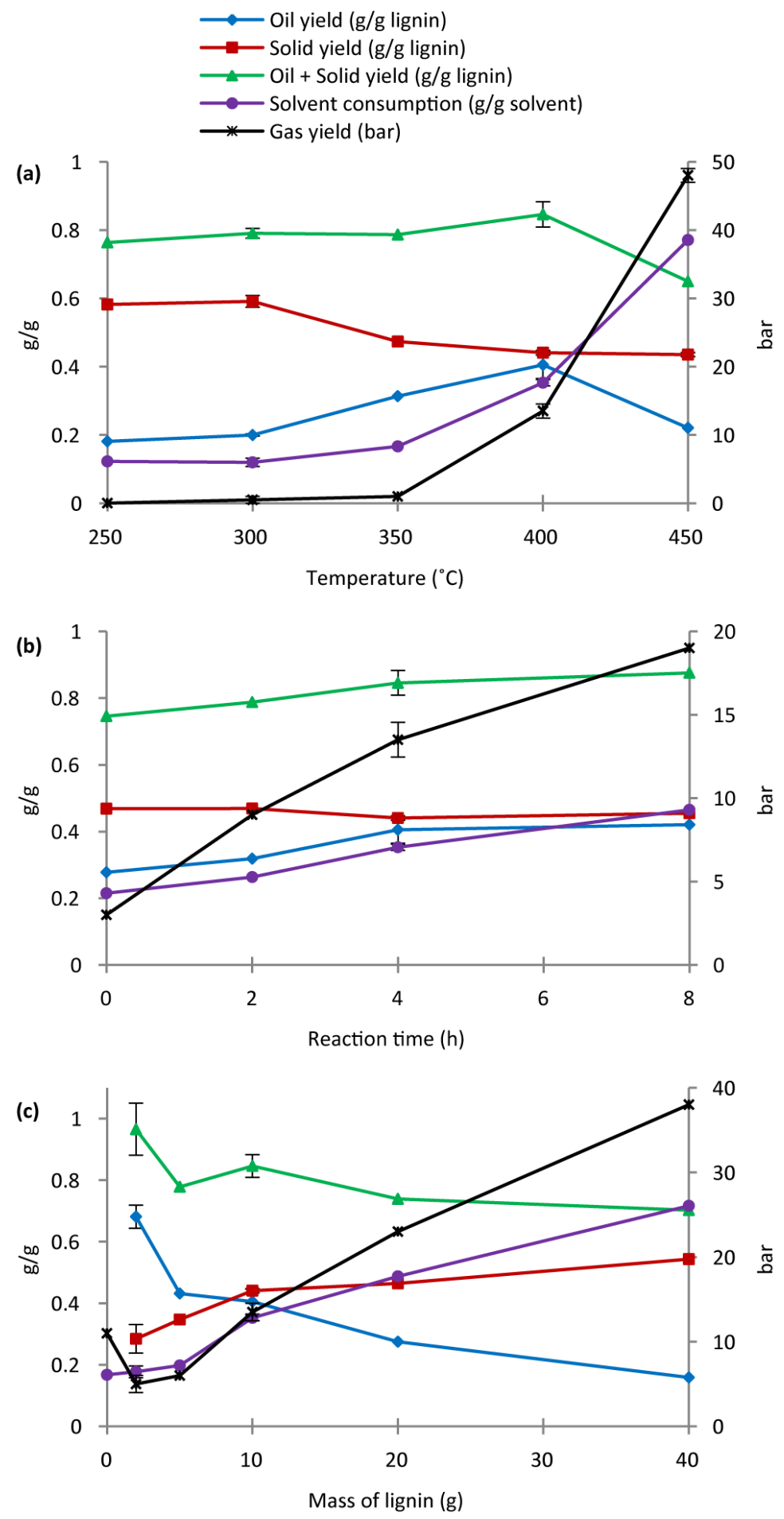

Figure 2. The oil yield, residual solid yield and sum of oil and residual solid yield are represented together with gas yield and amount of solvent consumed/lost as a function of reaction temperature (a), reaction time (b) and amount of lignin added (c). Oil yield, residual solid yield 
and sum of oil and residual solid yield are represented per lignin added (w:w) and amount of solvent consumption/loss is represented per solvent initially added (w:w). Conditions: $10 \mathrm{~g}$ lignin and $4 \mathrm{~h}$ reaction time (top); $10 \mathrm{~g}$ lignin and $400^{\circ} \mathrm{C}$ reaction temperature (middle); $4 \mathrm{~h}$ reaction time and $400^{\circ} \mathrm{C}$ reaction temperature (bottom). Error bars represent standard error of the mean. 

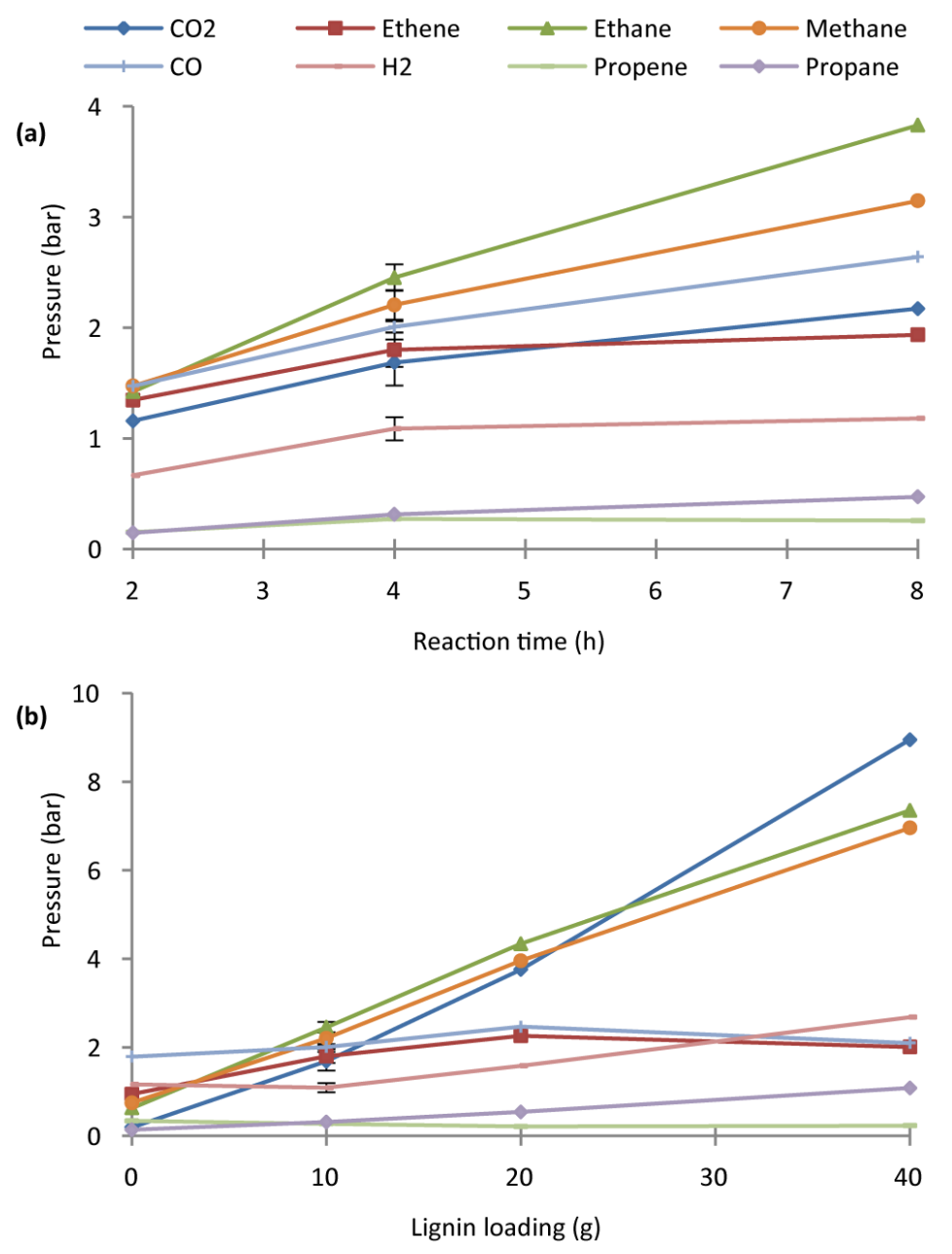

Figure 3. Final pressure (gauge pressure) at room temperature of different gasses formed as a function of reaction time for the solvolysis of $10 \mathrm{~g}$ lignin in $100 \mathrm{ml}$ ethanol at $400^{\circ} \mathrm{C}$ (a) and as a function of lignin loading for the lignin solvolysis in $100 \mathrm{ml}$ ethanol at $400^{\circ} \mathrm{C}$ for $4 \mathrm{~h}(\mathrm{~b})$. Error bars represent standard error of the mean. 


$$
\square<60 \mathrm{ppm} \quad \square 60-100 \mathrm{ppm} \quad \square 100-160 \mathrm{ppm} \quad \square 160-180 \mathrm{ppm}
$$
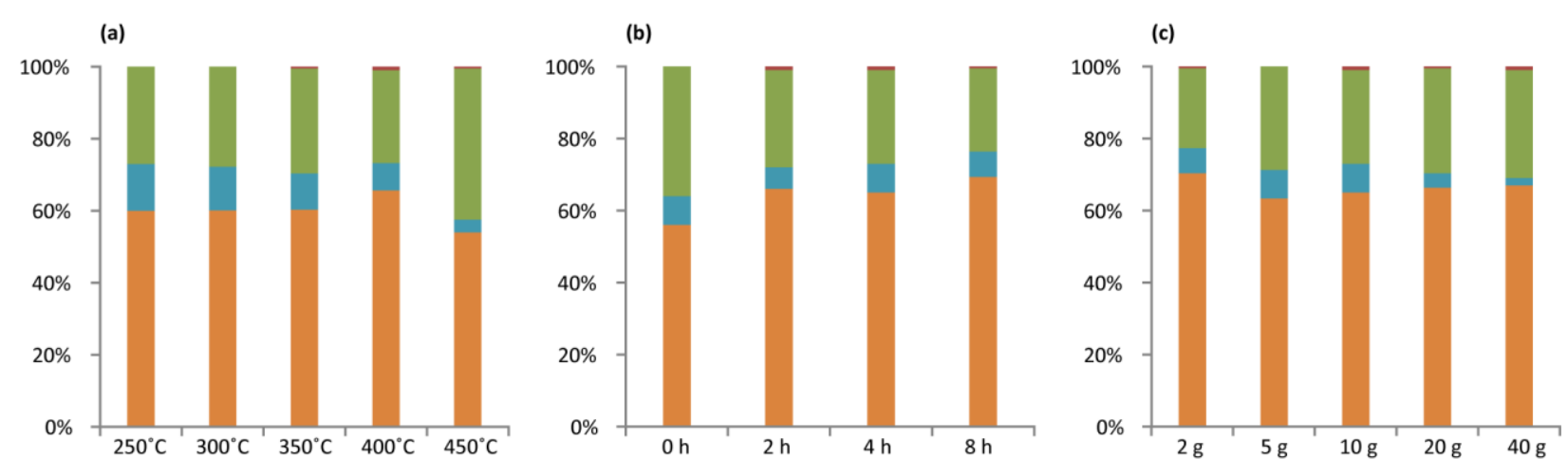

Figure $4 .{ }^{13} \mathrm{C}$ NMR integrals of lignin oils normalized to $100 \%$. The lignin oils are obtained at different reaction temperatures (a), reaction times (b), and degrees of lignin loading (c). Chemical shifts $<60 \mathrm{ppm}$ originate from the aliphatic fraction, $60-100 \mathrm{ppm}$ from the oxygenated $\mathrm{sp}^{3}, 100-160 \mathrm{ppm}$ from the aromatic fraction and 160-180 ppm from the carboxylic acid and ester fraction of the bio-oil. Reaction conditions for the produced oils: $10 \mathrm{~g}$ lignin and $4 \mathrm{~h}$ reaction time (a); $10 \mathrm{~g}$ lignin and $400^{\circ} \mathrm{C}$ reaction temperature (b); $4 \mathrm{~h}$ reaction time and $400^{\circ} \mathrm{C}$ reaction temperature (c). 

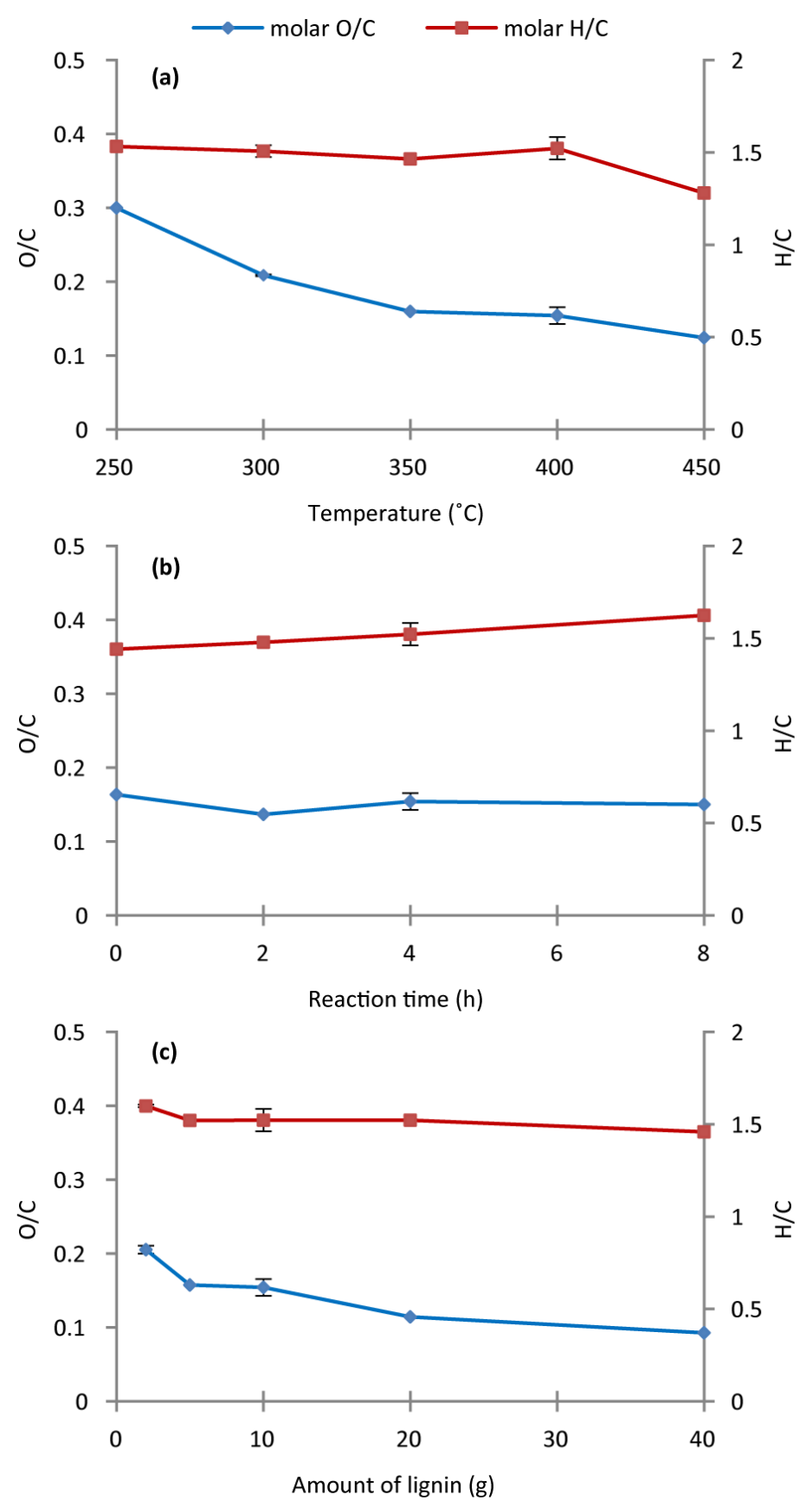

Figure 5. Molar $\mathrm{O} / \mathrm{C}$ and $\mathrm{H} / \mathrm{C}$ ratio in the oil product plotted as a function of reaction temperature (a), reaction time (b) and degree of lignin loading (c) for different reaction conditions. Reaction conditions: $10 \mathrm{~g}$ lignin and $4 \mathrm{~h}$ reaction time (a); $10 \mathrm{~g}$ lignin and $400^{\circ} \mathrm{C}$ reaction temperature (b); $4 \mathrm{~h}$ reaction time and $400^{\circ} \mathrm{C}$ reaction temperature (c). Error bars represent standard error of the mean. 

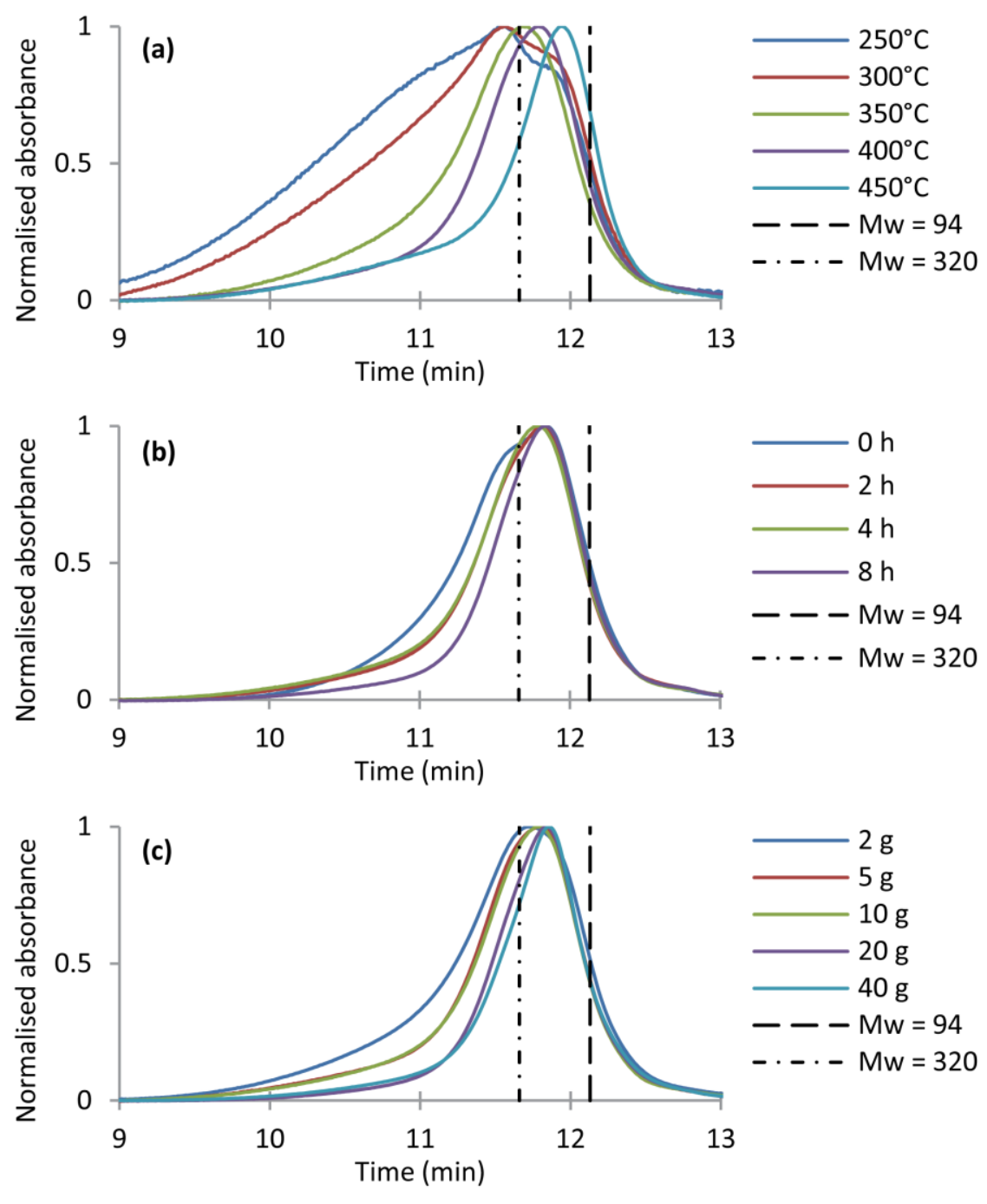

Figure 6. Molecular mass distribution for lignin oils obtained at different reaction temperatures (a), reaction times (b), and degrees of lignin loading (c). Size exclusion chromatography was conducted and the normalized absorbance at $280 \mathrm{~nm}$ wave length is shown as a function of elution time. Reaction conditions for produced oils: $10 \mathrm{~g}$ lignin and $4 \mathrm{~h}$ reaction time (a); $10 \mathrm{~g}$ lignin and $400^{\circ} \mathrm{C}$ reaction temperature (b); $4 \mathrm{~h}$ reaction time and $400^{\circ} \mathrm{C}$ reaction temperature (c). 


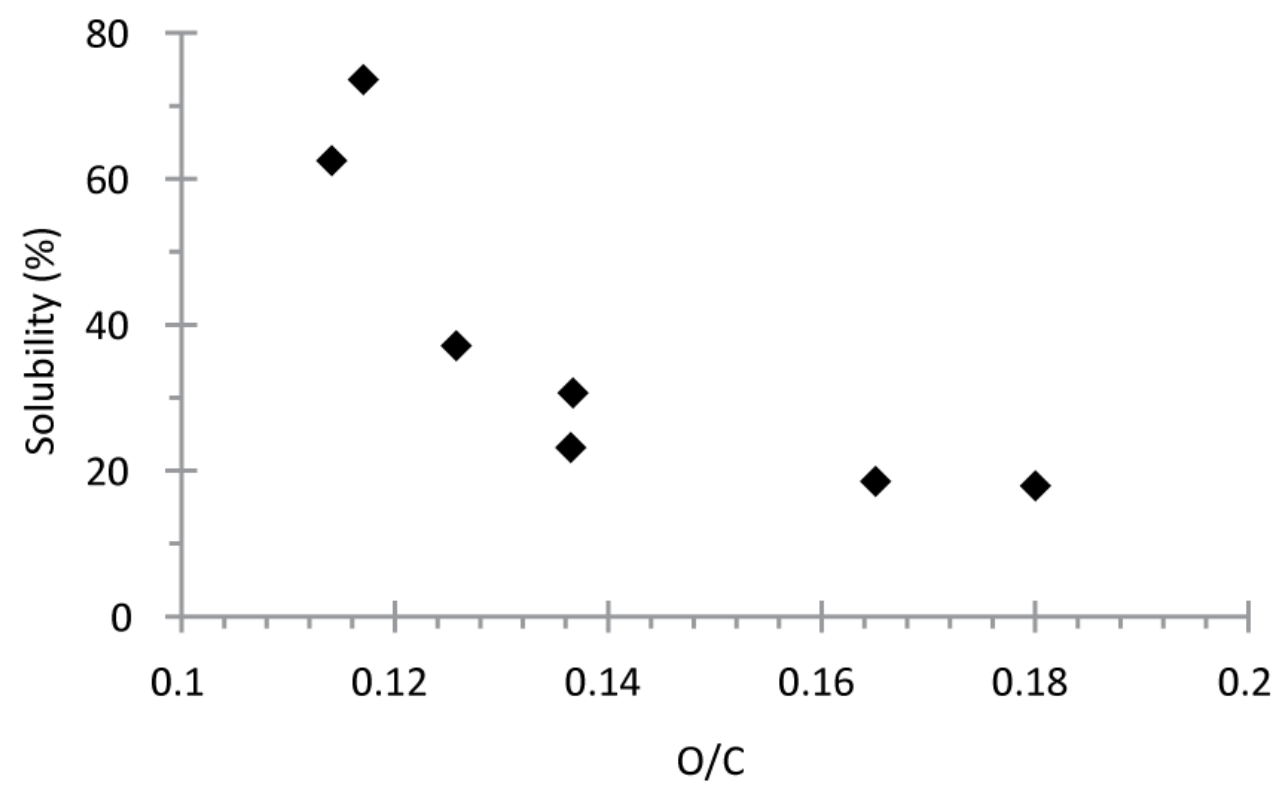

Figure 7. Solubility of lignin-oils in heptane as a function of molar O/C. Solubility is defined as the weight percent of heptane soluble oil with a mixing ratio of 1:9 (oil:heptane). 

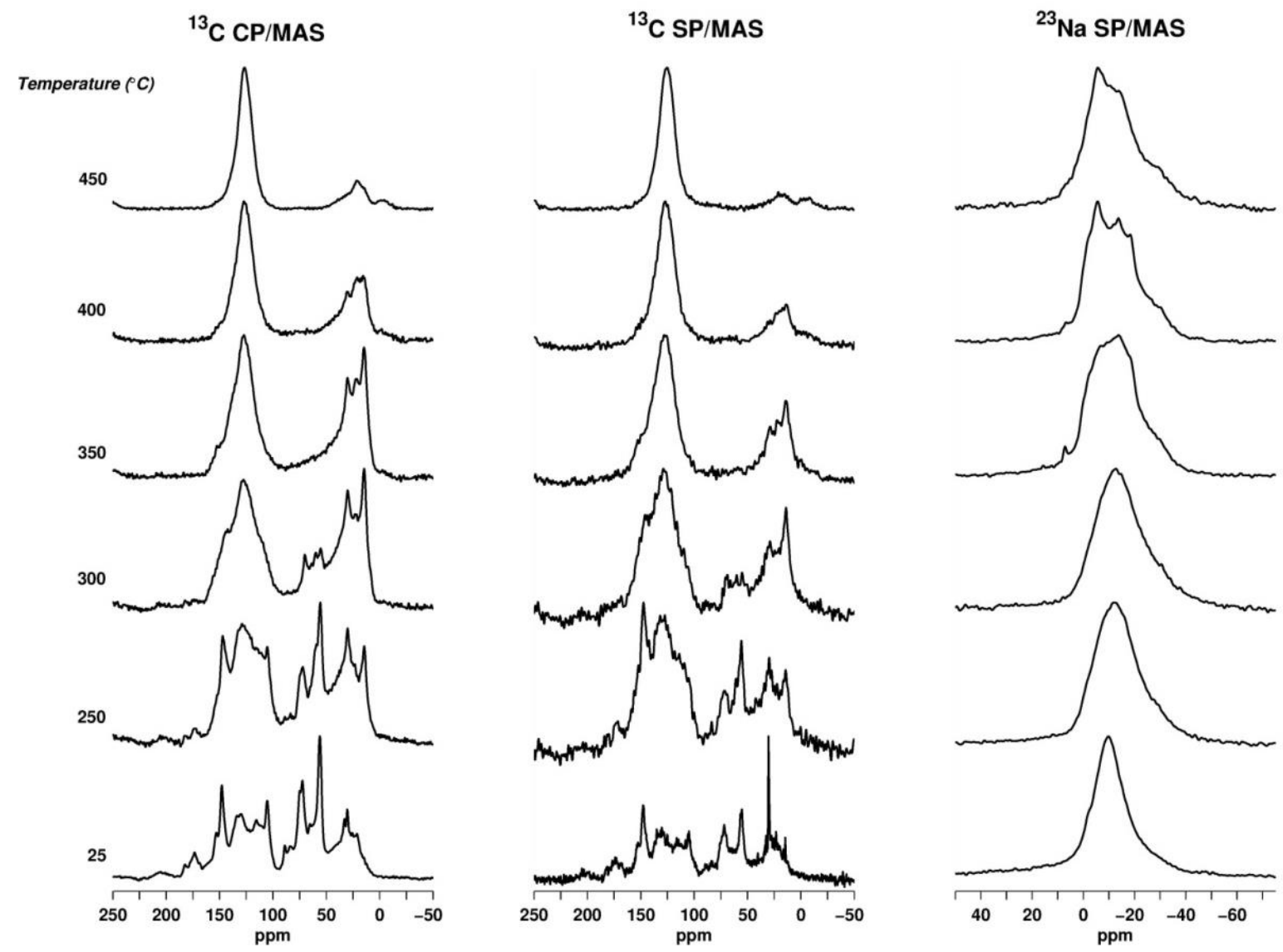

Figure $8 .{ }^{13} \mathrm{C}$ and ${ }^{23} \mathrm{Na}$ solid state MAS NMR of the residual solids from conducting solvolysis of $10 \mathrm{~g}$ lignin in $100 \mathrm{ml}$ ethanol for $4 \mathrm{~h}$ at different reaction temperatures. The sample at $25{ }^{\circ} \mathrm{C}$ is the solid lignin rich starting material. 


\section{ASSOCIATED CONTENT}

Supporting Information contains:

Lignin rich feedstock composition, additional product yield data, water gas shift reaction, stability of bio-oil, ${ }^{13} \mathrm{C}-\mathrm{HMBC}$ NMR data, ${ }^{13} \mathrm{C}-\mathrm{HSQC}$ NMR data, additional elemental analysis data, additional elemental analysis data, additional size exclusion chromatography data, full solid state NMR data.

This material is available free of charge via the Internet at http://pubs.acs.org.

\section{AUTHOR INFORMATION}

\section{Corresponding Author}

*E-mail: aj@kt.dtu.dk or cf@ign.ku.dk

\section{Author Contributions}

The manuscript was written through contributions of all authors. All authors have given approval to the final version of the manuscript.

\section{Funding Sources}

Funding through Innovation Fund Denmark under the project Biomass for the $21^{\text {st }}$ Century

\section{ACKNOWLEDGMENT}

The authors would like to thank Innovation Fund Denmark for funding under the Biomass for the $21^{\text {st }}$ Century project. 


\author{
ABBREVIATIONS \\ CP Cross polarization \\ d.a.f. Dry and ash free \\ FID Flame ionization detector \\ G Guaicyl \\ GC Gas chromatography \\ $\mathrm{H} \quad$-hydroxyphenyl \\ HHV Higher heating value
}

HMBC Heteronuclear multiple-bond correlation spectroscopy

HSQC Heteronuclear single-quantum correlation spectroscopy

MAS Magic angle spinning

MS Mass spectroscopy

NMR Nuclear magnetic resonance

o.d. Outer diameter

PAH Polyaromatic hydrocarbon

S Syringyl

SEC Size exclusion chromatography

SP Single pulse 
TCD Thermal conductivity detector

TPPM Two pulse phase modulation

\section{REFERENCES}

1. Larsen, J.; Haven, M. Ø.; Thirup, L., Inbicon makes lignocellulosic ethanol a commercial reality. Biomass Bioenergy 2012, 46 (0), 36-45.

2. Behling, R.; Valange, S.; Chatel, G., Heterogeneous catalytic oxidation for lignin valorization into valuable chemicals: what results? What limitations? What trends? Green Chemistry 2016, 18 (7), 1839-1854.

3. Li, S.-H.; Liu, S.; Colmenares, J. C.; Xu, Y.-J., A sustainable approach for lignin valorization by heterogeneous photocatalysis. Green Chemistry 2016, 18 (3), 594-607.

4. Zakzeski, J.; Bruijnincx, P. C. A.; Jongerius, A. L.; Weckhuysen, B. M., The Catalytic Valorization of Lignin for the Production of Renewable Chemicals. Chem. Rev. 2010, 110 (6), 3552-3599.

5. Saake, B.; Lehnen, R., Lignin. In Ullmann's Encyclopedia of Industrial Chemistry, Wiley-VCH verlag GmbH \& Co: Weinheim, 2012; Vol. 21, pp 21-36.

6. $\quad$ Trinh, T. N.; Jensen, P. A.; Sárossy, Z.; Dam-Johansen, K.; Knudsen, N. O.; Sørensen, H. R.; Egsgaard, H., Fast Pyrolysis of Lignin Using a Pyrolysis Centrifuge Reactor. Energy \& Fuels 2013, 27 (7), 3802-3810.

7. Zhao, W.; Xu, W.-J.; Lu, X.-J.; Sheng, C.; Zhong, S.-T.; Tang, S.-R.; Zong, Z.-M.; Wei, X.-Y., Preparation and Property Measurement of Liquid Fuel from Supercritical Ethanolysis of Wheat Stalk. Energ Fuel 2010, 24, 136-144.

8. Song, Q.; Wang, F.; Cai, J.; Wang, Y.; Zhang, J.; Yu, W.; Xu, J., Lignin depolymerization (LDP) in alcohol over nickel-based catalysts via a fragmentationhydrogenolysis process. Energy \& Environmental Science 2013, 6 (3), 994-1007.

9. Ye, Y.; Fan, J.; Chang, J., Effect of reaction conditions on hydrothermal degradation of cornstalk lignin. J Anal Appl Pyrol 2012, 94, 190-195.

10. Kuznetsov, B. N.; Sharypov, V. I.; Kuznetsova, S. A.; Taraban'ko, V. E.; Ivanchenko, N. M., The study of different methods of bio-liquids production from wood biomass and from biomass/polyolefine mixtures. Int J Hydrogen Energ 2009, 34, 7051-7056.

11. Yoshikawa, T.; Yagi, T.; Shinohara, S., Production of phenols from lignin via depolymerization and catalytic cracking. Fuel Process Technol 2013, 108.

12. Heitz, M.; Brown, A.; Chornet, E., Solvent effects on liquefaction: Solubilization profiles of a Canadian prototype wood, Populus deltoides, in the presence of different solvents. Can J Chem Eng 1994, 72, 1021-1027.

13. Cheng, S.; D'Cruz, I.; Wang, M.; Leitch, M.; Xu, C. C.; D'cruz, I., Highly Efficient Liquefaction of Woody Biomass in Hot-Compressed Alcohol-Water Co-solvents. Energ Fuel 2010, 24, 4659-4667. 
14. Ye, Y.; Zhang, Y.; Fan, J.; Chang, J., Novel Method for Production of Phenolics by Combining Lignin Extraction with Lignin Depolymerization in Aqueous Ethanol. Industrial \& Engineering Chemistry Research 2012, 51 (1), 103-110.

15. Pandey, M. P.; Kim, C. S., Lignin Depolymerization and Conversion: A Review of Thermochemical Methods. Chemical Engineering \& Technology 2011, 34 (1), 29-41.

16. Minami, E.; Saka, S., Comparison of the decomposition behaviors of hardwood and softwood in supercritical methanol. J Wood Sci 2003, 49, 73-78.

17. Lee, Y.-Y.; Lee, B.-H., Solvent-phase thermal cracking of lignin for production of potential liquid fuels. Journal of Industrial and Engineering Chemistry (Seoul) 1998, 4, 334-339.

18. Kim, J.-Y.; Oh, S.; Hwang, H.; Cho, T.-s.; Choi, I.-G.; Choi, J. W., Effects of various reaction parameters on solvolytical depolymerization of lignin in sub- and supercritical ethanol. Chemosphere 2013, 93 (9), 1755-1764.

19. Güvenatam, B.; Heeres, E. H. J.; Pidko, E. A.; Hensen, E. J. M., Lewis-acid catalyzed depolymerization of Protobind lignin in supercritical water and ethanol. Catal. Today 2016, 259, Part 2, 460-466.

20. Kuznetsov, B. N.; Sharypov, V. I.; Chesnokov, N. V.; Beregovtsova, N. G.; Baryshnikov, S. V.; Lavrenov, A. V.; Vosmerikov, A. V.; Agabekov, V. E., Lignin conversion in supercritical ethanol in the presence of solid acid catalysts. Kinet. Catal. 2015, 56 (4), 434-441.

21. Barta, K.; Matson, T. D.; Fettig, M. L.; Scott, S. L.; Iretskii, A. V.; Ford, P. C., Catalytic disassembly of an organosolv lignin via hydrogen transfer from supercritical methanol. Green Chemistry 2010, 12 (9), 1640-1647.

22. Kleinert, M.; Barth, T., Towards a Lignincellulosic Biorefinery: Direct One-Step Conversion of Lignin to Hydrogen-Enriched Biofuel. Energy \& Fuels 2008, 22 (2), 1371-1379.

23. Miller, J. E.; Evans, L.; Littlewolf, A.; Trudell, D. E., Batch microreactor studies of lignin and lignin model compound depolymerization by bases in alcohol solvents. Fuel 1999, 78 (11), 1363-1366.

24. Nielsen, J. B.; Jensen, A.; Jensen, A. D. Diesel-soluble lignin oils and methods of their production. WO2016113280, 2016.

25. Mansfield, S. D.; Kim, H.; Lu, F.; Ralph, J., Whole plant cell wall characterization using solution-state 2D NMR. Nat. Protocols 2012, 7 (9), 1579-1589.

26. Bennett, A. E.; Rienstra, C. M.; Auger, M.; Lakshmi, K. V.; Griffin, R. G., Heteronuclear decoupling in rotating solids. The Journal of Chemical Physics 1995, 103 (16), 6951-6958.

27. Metz, G.; Wu, X. L.; Smith, S. O., Ramped-Amplitude Cross Polarization in MagicAngle-Spinning NMR. Journal of Magnetic Resonance, Series A 1994, 110 (2), 219-227.

28. Pandey, M. P.; Kim, C. S., Lignin depolymerization and conversion: a review of thermochemical methods. Chem Eng Technol 2011, 34, $29-41$.

29. Yip, J.; Chen, M.; Szeto, Y. S.; Yan, S., Comparative study of liquefaction process and liquefied products from bamboo using different organic solvents. Bioresource Technol 2009, 100, 6674-8.

30. Soria, A. J.; McDonald, A. G.; Shook, S. R., Wood solubilization and depolymerization using supercritical methanol. Part 1: Process optimization and analysis of methanol insoluble components (bio-char). Holzforschung 2008, 62, 402-408.

31. Soria, A. J.; McDonald, A. G.; He, B. B., Wood solubilization and depolymerization by supercritical methanol. Part 2: analysis of methanol soluble compounds. Holzforschung 2008, 62, 409-416. 
32. Li, J.; Henriksson, G.; Gellerstedt, G., Lignin depolymerization/repolymerization and its critical role for delignification of aspen wood by steam explosion. Bioresour. Technol. 2007, 98 (16), 3061-3068.

33. Barnard, J. A.; Hughes, H. W. D., The pyrolysis of ethanol. Transactions of the Faraday Society 1960, $56(0), 55-63$.

34. Adjaye, J. D.; Sharma, R. K.; Bakhshi, N. N., Characterization and stability analysis of wood-derived bio-oil. Fuel Process. Technol. 1992, 31 (3), 241-256.

35. Yelle, D.; Kaparaju, P.; Hunt, C.; Hirth, K.; Kim, H.; Ralph, J.; Felby, C., Twodimensional NMR evidence for cleavage of lignin and xylan substituents in wheat straw through hydrothermal pretreatment and enzymatic hydrolysis. Bioenergy Res. 2013, 6 (1), 211-221.

36. Parthasarathi, R.; Romero, R. A.; Redondo, A.; Gnanakaran, S., Theoretical Study of the Remarkably Diverse Linkages in Lignin. The Journal of Physical Chemistry Letters 2011, 2 (20), 2660-2666.

37. Parikh, J.; Channiwala, S.; Ghosal, G., A correlation for calculating HHV from proximate analysis of solid fuels. Fuel 2005, 84 (5), 487-494.

38. Hansen, V.; Müller-Stöver, D.; Ahrenfeldt, J.; Holm, J. K.; Henriksen, U. B.; HauggaardNielsen, H., Gasification biochar as a valuable by-product for carbon sequestration and soil amendment. Biomass Bioenergy 2015, 72, 300-308.

39. Hanaya, M.; Harris, R. K., Two-dimensional 23 Na MQ MAS NMR study of layered silicates. J. Mater. Chem. 1998, 8 (4), 1073-1079.

40. Xue, X.; Stebbins, J. F., 23 Na NMR chemical shifts and local Na coordination environments in silicate crystals, melts and glasses. Phys. Chem. Miner. 1993, 20 (5), 297-307.

41. Nielsen, J. B. Valorization of lignin from biorefineries for fuels and chemicals. PhD thesis, Technical University of Denmark, 2016. 